\title{
Preliminary Test Results for the MICE Spectrometer Superconducting Solenoids
}

\author{
S. P. Virostek, M. A. Green Member IEEE, D. Li, M. S. Zisman, S. T. Wang, Member IEEE, \\ R. Wahrer, C. Taylor, X. Lu, J. Y. Chen, M. Wang, and T. Juang
}

\begin{abstract}
This report describes the MICE spectrometer solenoids as built. Each magnet consists of five superconducting coils. Two coils are used to tune the beam going from or to the MICE spectrometer from the rest of the MICE cooling channel. Three spectrometer coils (two end coils and a long center coil) are used to create a uniform $4 \mathrm{~T}$ field (to \pm 0.3 percent) over a length of $1.0 \mathrm{~m}$ within a diameter of $0.3 \mathrm{~m}$. The three-coil spectrometer set is connected in series. The two end coils use small power supplies to tune the uniform field region where the scintillating fiber tracker is located. This paper will present the results of the preliminary testing of the first spectrometer solenoid.
\end{abstract}

Index Terms-Superconducting Solenoid and 4 K Coolers

\section{INTRODUCTION}

$\mathrm{T}$ HE development of a muon collider and neutrino factory requires that beams of low emittance muons be produced. Muon ionization cooling is the key accelerating and storing muons [1]. Muon cooling will be demonstrated by the Muon Ionization Cooling Experiment (MICE) at the Rutherford Appleton Laboratory in the UK [2]. MICE is a channel of superconducting solenoid magnets and liquid absorbers.

The MICE cooling channel consists of three types of solenoids, which are: 1) the focusing magnets that are around the liquid hydrogen absorbers [3], 2) the coupling solenoids that are around the RF cavities that re-accelerate the muons after they have cooled by the absorber [4], and 3) the spectrometer magnets that provide the uniform magnetic field needed to analyze the properties of the muons entering and leaving the MICE cooling channel [5].

The magnet has five superconducting coils. Two of these coils M1 and M2 are used to match the muon beam with the adjacent focusing magnet module (two coils and an absorber). The remaining three coils (E1, center, and E2) form a spectrometer magnet that produces a uniform magnetic field (to within \pm 0.3 percent) within a region that is 1.0 meter long and 0.3 meters in diameter. A five-plane scintillating fiber

Manuscript received 19 August 2008. This work was supported by the Office of Science US Department of Energy under DOE contract DE-AC0205CH11231. DOE funding for the US Neutrino Factory Muon Collider Collaboration is greatly appreciated.

S. P. Virostek. M. A. Green, D. Li and M. S. Zisman are from the Lawrence Berkeley National Laboratory, Berkeley, CA 94720, USA. The corresponding author is M. A. Green: +1-510-486-5598; Fax: +1-510-4866668; e-mail: magreen@lbl.gov.gov). S. T. Wang, C. Taylor, X. Lu, J, Y. Chen, M. Wang, and T. Juang are from Wang NMR, Livermore CA, USA detector is used to analyze the emittance of the muons.

\section{SPECTROMETER SOLENOID DESIGN AND FABRICATION}

The magnet is divided into the match section and the spectrometer section. The match section consists of two coils that are 201.2 and $199.5 \mathrm{~mm}$ long. The two match coils (M1 and M2) are separated by a space of about $240 \mathrm{~mm}$. The spectrometer section consists of three coils. The center coil is designed with a length of $1314.3 \mathrm{~mm}$. There are two end coils that are each $110.6 \mathrm{~mm}$ long. The space between the two end coils and the center coil is about $38 \mathrm{~mm}$. The space between the second match coil M2 and the first spectrometer coil E1 is a bit over $244 \mathrm{~mm}$. The space between the two match coils and the second match coil and the spectrometer section is necessary in order for the match between the focusing magnet and the spectrometer section to be achieved. (This is similar to a quadrupole triplet where the space between the quads is needed to get the appropriate focusing.) A three-dimensional schematic view of the spectrometer magnet is shown in Fig. 1.

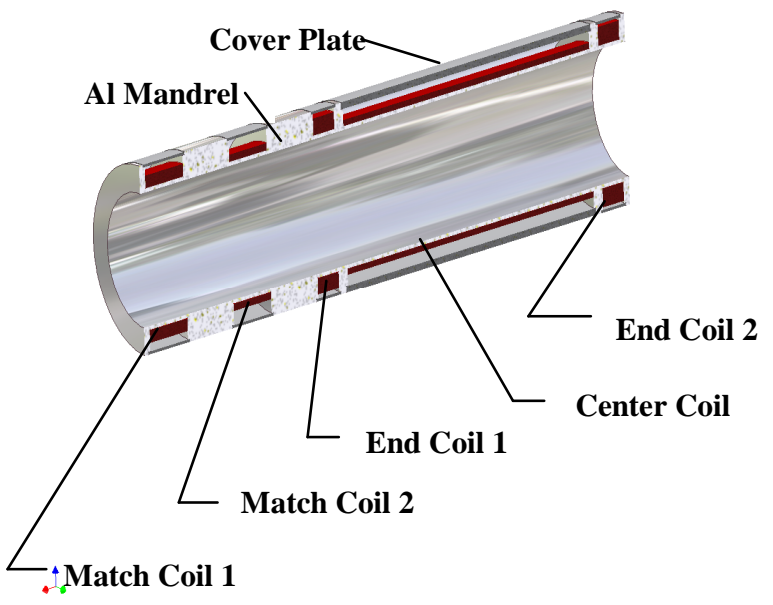

Fig. 1. A 3-D View of the Spectrometer Solenoid Cold Mass.

The magnet module length is $2923 \mathrm{~mm}$. The cryostat vacuum vessel length is $2735 \mathrm{~mm}$. The magnet warm bore is $400 \mathrm{~mm}$. The OD of the magnet module is $1404 \mathrm{~mm}$. The magnet cold mass length is $2554 \mathrm{~mm}$. The cold mass inner diameter is $490 \mathrm{~mm}$ and the outer diameter is $724 \mathrm{~mm}$.

The magnet coils are powered using three 300-A power supplies. Two of the power supplies power each of the match coils. The third supply powers the spectrometer section. Two 
60-A power supplies are used to adjust the currents in the two end coils of the spectrometer section of the magnet.

The magnet coils were wet wound on an aluminum mandrel made from a single 6061-T6 forging. After the coils were wound they were banded with aluminum. After the coils have been wound and banded, the quench protection diodes and resistors were installed on the outside of the coils. The purpose of the diodes and resistors is to reduce the peak voltages in the magnet coils and the quench hot spot temperature [6], [7]. Once the quench protection system was installed, the cold mass assembly cover was installed creating a helium vessel that holds $\sim 180$ liters of liquid helium. The magnet $\mathrm{Nb}$-Ti leads were installed through a vacuum tight feed through developed by Wang NMR. The magnet vent pipes and piping for the re-condensation were installed. The cold mass vessel was pressurized and vacuum leak checked.

Table I shows the basic dimensions of the second of the two-spectrometer solenoids that were wound at the vendor's shop. The second solenoid is more uniform in its turnsdensity than is the first magnet. It turns out that this does not make a great deal of difference in the scheme of things, because the effect on the beam dynamics of the muon beam in the MICE channel is of second order [8].

Table II compares the second solenoid with the first solenoid. There are small differences in the average radial position of the current center for each of the coils. Increasing the current center radius decreases the field on axis, but the integrated field due to the coil current does not change to first order [8]. The longitudinal position of the magnet coil current centers is within \pm 50 microns on the mandrels. The real issue is that the mandrel position within the cryostat with respect to the vacuum shell end plates may be off by as much as $\pm 1 \mathrm{~mm}$. In general a $1 \mathrm{~mm}$ longitudinal position error will not make a difference in the performance of the beam within the MICE cooling channel [9]. The biggest difference between the two coils is the number of turns in the center coil.
The biggest difference between the two magnets is the number of turns in the center coil of the three-coil spectrometer section. The second magnet has eight turns more in the center coil than first magnet. This means that the number of ampere-turns in the second magnet center coil is 0.05 percent more than the first magnet center coil. The reason for the change in the number of turns is that the winding crew had to learn how to wind the magnet in a uniform fashion.

\section{MAGNet Assembly AND MAGNET CoOLING}

The MICE spectrometer solenoids are designed to be cooled using three Cryomech PT415 pulse tube coolers. These coolers each provide $1.5 \mathrm{~W}$ of cooling at $4.2 \mathrm{~K}$ while providing $55 \mathrm{~W}$ of cooling at $60 \mathrm{~K}$. The coolers provide cooling for both the magnet cold mass and the magnet shield. The projected heat load at $4 \mathrm{~K}$ is over $3 \mathrm{~W}$, if the shield and cold mass support intercepts are a $80 \mathrm{~K}$ or below. There are three pairs of 300-A HTS and copper leads and a single pair of 60-A leads that connect the magnet coils to the outside world. The projected heat leak down the eight copper leads is $\sim 92 \mathrm{~W}$. The top of the HTS leads must be less than $60 \mathrm{~K}$.

The connection between the top of the HTS leads and room temperature is through conductively cooled copper leads that connect room temperature (see Fig. 2). When the magnet is powered at full current, the projected heat load to the cooler first stage from the copper leads is $\sim 92 \mathrm{~W}$ when they are powered [10]. When optimum leads (minimum heat leak leads) are not powered the heat load should be $46 \mathrm{~W}$ [11]. The rest of the magnet heat loads into the cooler first stage are supposed to be in the range from 30 to $40 \mathrm{~W}$.

TABle I. The As BuILt PARAMETERS FOR THE SECOND SPECTROMETER SOLENOID

\begin{tabular}{lccccc}
\hline \hline & Match 1 & Match 2 & End 1 & Center & End 2 \\
\hline Inner Coil Radius (mm) & 258 & 258 & 258 & 258 & 258 \\
Coil Thickness (mm) & 46.165 & 30.925 & 60.905 & 22.125 & 67.783 \\
Coil Length (mm) & 201.268 & 199.492 & 110.642 & 1314.30 & 110.642 \\
Current Center Axial Position* (mm) & 124.00 & 564.00 & 964.00 & 1714.00 & 2464.00 \\
Current Center Radial Position* (mm) & 281.083 & 273.463 & 288.453 & 269.063 & 291.891 \\
Coil Average J (A mm ${ }^{-2}$ ) & 137.67 & 147.77 & 124.28 & 147.66 & 127.09 \\
Number of layers per Coil & 42 & 28 & 56 & 20 & 62 \\
Number of Turns per Layer & 115 & 114 & 64 & 768 & 64 \\
Total Number of Turns & 4830 & 3192 & 3584 & 15360 & 3968 \\
Design Current (A)** & 264.83 & 285.60 & 233.68 & 275.52 & 240.21 \\
Coil Self Inductance (H)^ & 12.0 & 5.0 & 9.0 & 40.0 & 11.3 \\
Coil Stored Energy (MJ)** & 0.42 & 0.20 & 0.26 & 1.55 & 0.32 \\
Peak Field in Coil (T)** & 5.30 & 4.32 & 5.68 & 4.24 & 5.86 \\
Temperature Margin at 4.2 K (K)** & $\sim 1.6$ & $\sim 1.8$ & $\sim 1.5$ & $\sim 2.0$ & $\sim 1.5$ \\
\hline
\end{tabular}

* $\quad$ Based on $\mathrm{Z}=0$ is at the match coil end of the magnet cold mass. (The center of MICE in these coordinates is at $\mathrm{Z}=-3487 \mathrm{~mm}$.) $\mathrm{R}=0$ is the axis of the magnet (the MICE axis).

** This is at the maximum design current, which is based on the worst-case currents for the five coils. 
$\wedge \quad$ The inductance of the two end coils and the center coil in series is about $74 \mathrm{H}$.

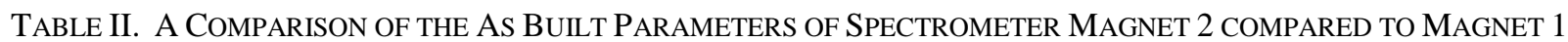

\begin{tabular}{lccccc}
\hline \hline Parameter & Match 1 & Match 2 & End 1 & Center & End 2 \\
\hline Inner Coil Radius (mm) & $< \pm 0.01$ & $< \pm 0.01$ & $< \pm 0.0$ & $< \pm 0.01$ & $< \pm 0.01$ \\
Coil Thickness (mm) & -0.318 & +0.317 & -0.732 & -0.291 & -0.437 \\
Coil Length $(\mathrm{mm})$ & 0.068 & -0.008 & +0.042 & -0.001 & +0.042 \\
Current Center Axial Position^ $(\mathrm{mm})$ & \pm 0.05 & \pm 0.05 & \pm 0.05 & \pm 0.05 & \pm 0.05 \\
Current Center Radial Position^ $(\mathrm{mm})$ & -0.159 & +0.159 & -0.366 & -0.145 & -0.219 \\
Coil Average J (A mm $\left.{ }^{-2}\right)$ & +0.94 & -1.53 & +1.47 & +1.92 & +0.81 \\
Number of layers per Coil & 0 & 0 & 0 & 0 & 0 \\
Number of Turns per Layer & 0 & 0 & 0 & +2 to 0 & 0 \\
Total Number of Turns & 0 & 0 & 0 & +8 & 0 \\
Design Current (A)* & \pm 0.01 & \pm 0.01 & \pm 0.01 & -0.15 & \pm 0.01 \\
Coil Self Inductance $(\mathrm{H})$ & $\sim 0$ & $\sim 0$ & $\sim 0$ & $\sim 0$ & $\sim 0$ \\
Coil Stored Energy (MJ)* & $\sim 0.0$ & $\sim 0.0$ & $\sim 0.0$ & $\sim 0.0$ & $\sim 0.0$ \\
Peak Field in Coil (T)* & $\sim 0$ & $\sim 0$ & $\sim 0$ & $\sim 0$ & $\sim 0$ \\
Temperature Margin at 4.2 K (K)* & $\sim 0$ & $\sim 0$ & $\sim 0$ & $\sim 0$ & $\sim 0$ \\
\hline
\end{tabular}

$\wedge \quad$ The change in current position between the coils of the two magnets in the axial direction is with respect to the distance from end of the cold mass. The change in the position of the current center in the radial direction is with respect to the distance from axis of the solenoid

* This change is at the coil maximum design current, which is based on the worst-case currents for the five coils.

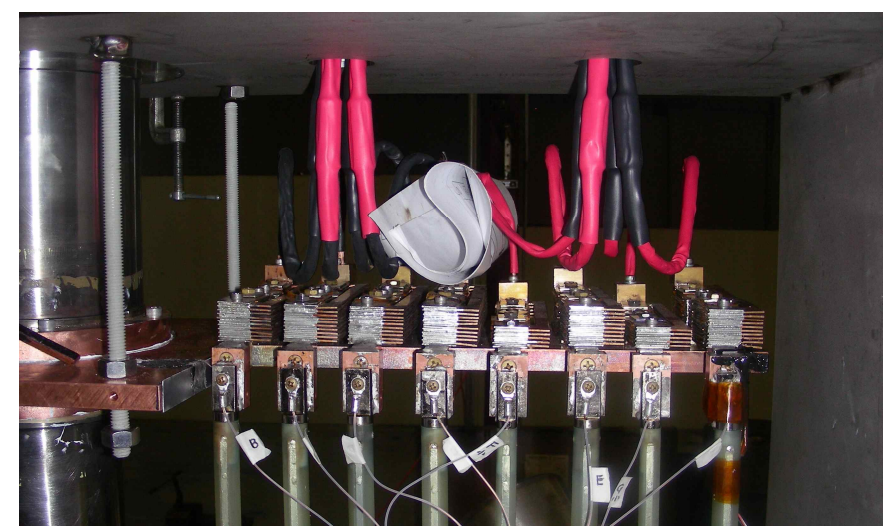

Fig. 2. The HTS and Copper Leads for the MICE Spectrometer Solenoid

\section{MAGNET COOL-DOWN AND OPERATION}

Magnet 1 was fully assembled in May of 2008. The magnet is $2923 \mathrm{~m}$ long, $1404 \mathrm{~mm}$ wide and $3250 \mathrm{~mm}$ high with a total mass in excess of 7 tons. Fig. 3 shows the fully assembled magnet before it was cooled down using liquid nitrogen and liquid helium. The magnet cool-down took the better part of two weeks because of stress limitation imposed by the weld between the cold mass cover plate and the mandrel upon which the magnet coils are wound. Care had to be taken to see that the cover plate temperature was less than $50 \mathrm{~K}$ different from the mandrel temperature at the start of the magnet cool-down. As the magnet mandrel temperature went down the allowable temperature difference could be relaxed. Once the mandrel temperature reached $150 \mathrm{~K}$ this limitation no longer applied.

The magnets are kept cold using coolers that are dropped into the top of the magnet. The use of drop-in coolers permits one to remove the coolers and ship them separately. Using drop in coolers makes installation at the Rutherford Appleton
Laboratory in the UK a bit easier. The problem with the use of drop in coolers is that from 0.2 to $0.3 \mathrm{~W}$ of cooling is lost when the cooler is installed in a drop-in cooler sleeve at the top of the magnet cryostat [12]. With three coolers installed on the magnet, the effective available cooling power at $4.2 \mathrm{~K}$ is from 3.6 to $3.9 \mathrm{~W}$ instead of $4.5 \mathrm{~W}$.

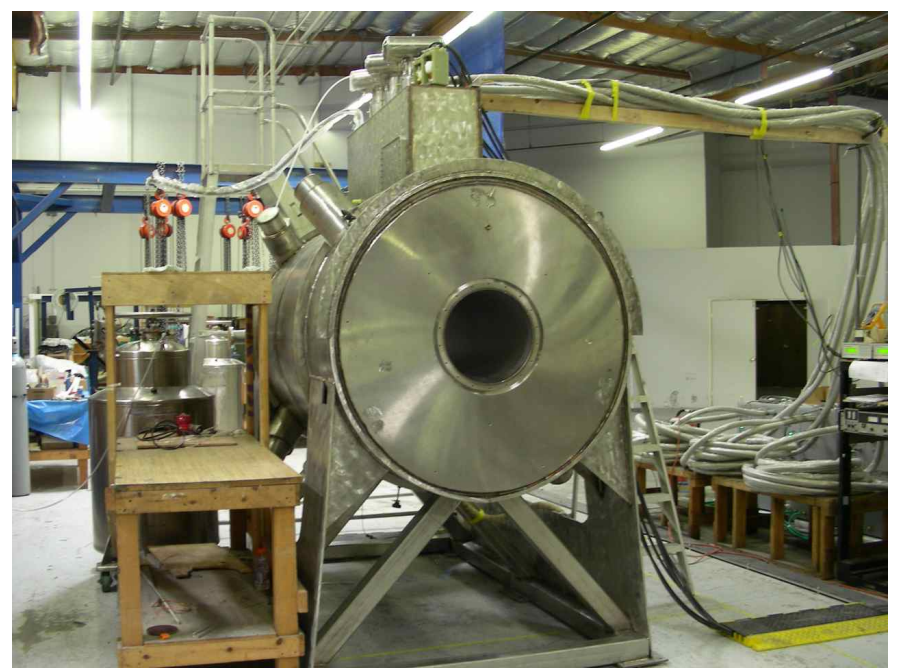

Fig. 3. Finished Spectrometer Solenoid 1 before the Magnet Cool-down

\section{TESTS OF THE FIRST MICE SPECTROMETER MAGNET}

The first spectrometer solenoid was tested at the vendor's factory during June and July of 2008. The magnet was trained to seventy percent of full operating in August of 2008 [13]. There were a number of problems uncovered during the cool down and testing of the magnet. First, the cool down took a long time. One reason for this was that the shield could not be cooled down before the magnet cold mass was cooled. This will be remedied by installing a liquid nitrogen tank connected directly to the aluminum-shield. 
Second, three PT drop in PT415 coolers did not keep the magnet cold during the test. There were a number of reasons for this. An average shield temperature of over $100 \mathrm{~K}$ was measured instead of the $80 \mathrm{~K}$ called for in the design. The excess shield temperature could be due to three causes: 1) The connection between the shield and the cooler first-stage is poor. There is some strong evidence for this scenario. 2) The total heat flow into the first stage of the coolers is too high. There is less evidence for this scenario because the top of the HTS leads was about $62 \mathrm{~K}$ when the magnet was cold. 3) The wrong aluminum was used for the shield.

There was a net helium boil-off of about 6 liters per hour yet the region around the second stage cold heads was from $3.4 \mathrm{~K}$ to $3.9 \mathrm{~K}$. The high boil off suggests an excess heat load of about $4 \mathrm{~W}$. The temperature at the cooler second stage is indicative of a poor thermal connection between the cooler cold heads and the cold mass. When the magnet was warmed up in the middle of August 2008, we found that the pipes connecting the condensers to the cold mass were plugged with nitrogen. Thus no cooling was delivered to the magnet cold mass from the second stage cold heads. The pipes being open are essential to delivering the cooling to the cold mass [14].

If there is no nitrogen in the helium space and if the magnet shield temperature can be brought down to $80 \mathrm{~K}$, operation of the magnet using three PT415 coolers will be assured.

There are two methods of bringing down the shield temperature. They are: 1) Intercept eighty percent of the lead coming down the leads from room temperature into a tank of liquid nitrogen. 2) Improve the thermal conduction between the shield and the first stage of the coolers. Calculations suggest that if the shield temperature can be brought down to $80 \mathrm{~K}$, the heat leak into the $4 \mathrm{~K}$ region will be less than $3.5 \mathrm{~W}$.

The cool down procedure for the magnet must be revised to keep liquid nitrogen from collecting in the helium volume around the coils and the pipes that connect the condenser to the magnet. The pipes connecting the condenser to the cold mass can also be made larger. There are other alternatives for ensuring that adequate re-condensation occurs.

\section{CONCLUDING COMMENTS}

The two-spectrometer solenoids are nearly identical to each other. The magnets are identical enough to permit them to be operated in series. This is true for the $300 \mathrm{~A}$ circuits and the 60 A circuits. The differences in the two-spectrometer magnets are expected to have no effect on the muon beam in the MICE cooling channel.

The first of two spectrometer solenoids for the MICE cooling channel has been assembled and tested at the vendor's plant. The second solenoid will be assembled within a month of the receipt of this paper by the publisher for review. Training of the first solenoid is nearly finished. The heat leak into the $4 \mathrm{~K}$ region of the first magnet appears to exceed the capacity of three PT415 coolers at $4.2 \mathrm{~K}$. There appears that the excessive heat leak into the $4 \mathrm{~K}$ region is due to excessive shield and cold mass support intercept temperatures. The connection between the second stage of the coolers and the cold mass was broken by the nitrogen ice in the cooler condenser to magnet thermal-siphon circuit.

The decision to use drop in coolers has resulted in the reduction of available cooling to the $4 \mathrm{~K}$ region of the magnet.
The temperature drop across the shield (and top of the HTS leads) and the first stage of the cooler contributes to the difficulties caused by the excessive magnet shield and intercept temperature. Further testing of the drop-in cooler concept may be required. Finally, we must ensure that the pipes connecting the condenser mounted on the second stage to the cold mass is not plugged with ice of any kind. More than one approach to ensuring that re-condensation occurs is being considered.

In the second magnet, the thermal conduction between the shield and the cooler first stage will be greatly improved. The shield on the second magnet will be pre-cooled using liquid nitrogen to improve the cool-down characteristics of the magnet as a whole. The first magnet, it will be retrofitted to match the second spectrometer solenoid.

One can reduce the temperature of the top of the HTS leads and the magnet shield by intercepting the heat coming down the copper leads between $300 \mathrm{~K}$ and the top of the HTS leads. Since the heat coming down the copper leads represents over 70 percent of the total heat into the cooler first stage, one can further reduce the shield temperature and thus reduce the heat flow into the $4 \mathrm{~K}$ region even further. We have decided not to intercept the heat coming down the copper leads.

\section{REFERENCES}

[1] R. B. Palmer, A. Sessler, A. Skrinsky, A. Tollestrup, et al, "Muon Colliders," Brookhaven National Laboratory Report BNL-62740, January 1996

[2] G. Gregoire, G. Ryckewaert, L. Chevalier, et al, "MICE and International Muon Ionization Experiment Technical Reference Document," http://mice.iit.edu 2002

[3] S. Q. Yang, M. A. Green, et al, "The Mechanical and Thermal Design for the MICE Focusing Solenoid Magnet System," IEEE Transactions on Applied Superconductivity 15, No. 2, p 1259, 2005.

[4] L. Wang, M. A. Green, F. Y. Xu, H, Wu, et al, "The Engineering Design of the $1.5 \mathrm{~m}$ Diameter Solenoid for the MICE RFCC Modules, IEEE Transactions on Applied Superconductivity 18, No. 2, p 937, 2008.

[5] M. A. Green, C. Y. Chen, T. Juang, W. Lau, et al, "The Design Parameters for the MICE Tracker Solenoid," IEEE Transactions on Applied Superconductivity 17, No. 2, p 1247, 2007.

[6] M. A. Green, L. Wang, X. L. Gou, F. Y Xu and L. X. Jia, "Quench Protection for the MICE Coupling Magnet," LBNL-63698, MICE Note 193, http://mice.iit.edu 20 November 2007.

[7] X. L. Gou, F. Y. Xu, L. Wang, M. A. Green et al, "Quench Protection for the MICE Cooling Channel Coupling Magnet," submitted to IEEE Transactions on Applied Superconductivity 19, No. 3 (this issue), 2009

[8] M. A. Green and S. P. Virostek, "The Dimensions and Number of Turns for the Spectrometer Solenoids As-Built compared to the Original magnet Design," MICE Note 207, http://mice.iit.edu June 2008

[9] John Cobb, Oxford University UK, private communication on the effect of MICE magnet coil placement on the quality of the MICE beam.

[10] M. N. Wilson, Superconducting Magnets, Oxford University Press, Oxford, 1983. p 209 to 219

[11] A. M. Kadin, R. J. Webber, and D. Gupta, "Current Leads and Optimized Thermal Packaging for Superconducting Systems on Multistage Coolers," IEEE Transactions on Applied Superconductivity 17, No. 2, p 975, 2007

[12] M. A. Green and S. T. Wang, "Tests of Four PT415 Coolers Installed in the Drop in Mode," to be published in the Proceedings of the $22^{\text {nd }}$ International Cryogenic Engineering Conference, Seoul Korea, 21 to 25 June 2008.

[13] S. T. Wang, R. Wahrer, C. Taylor, et al, "The Design, and Construction of the MICE Spectrometer Solenoids," submitted to IEEE Transactions on Applied Superconductivity 19, No. 3 (This Issue) 2009.

[14] M. A. Green, "How the Performance of a Superconducting Magnet is Affected by the Connection between a Small Cooler and the Magnet," IEEE Transactions on Applied Superconductivity 16, No. 1, p 1330, 2007 
DISCLAIMER

This document was prepared as an account of work sponsored by the United States Government. While this document is believed to contain correct information, neither the United States Government nor any agency thereof, nor The Regents of the University of California, nor any of their employees, makes any warranty, express or implied, or assumes any legal responsibility for the accuracy, completeness, or usefulness of any information, apparatus, product, or process disclosed, or represents that its use would not infringe privately owned rights. Reference herein to any specific commercial product, process, or service by its trade name, trademark, manufacturer, or otherwise, does not necessarily constitute or imply its endorsement, recommendation, or favoring by the United States Government or any agency thereof, or The Regents of the University of California. The views and opinions of authors expressed herein do not necessarily state or reflect those of the United States Government or any agency thereof, or The Regents of the University of California. 